\title{
PROGRAMA DE EDUCAÇÃO AMBIENTAL E AGRICULTURA FAMILIAR: ANÁLISE DA PROPOSTA PEDAGÓGICA
}

\author{
Alane Pereira de Oliveira ${ }^{1}$ \\ Liliane Caraciolo Ferreira ${ }^{2}$
}

\begin{abstract}
Resumo: O presente artigo objetiva analisar como o Programa de Educação Ambiental e Agricultura Familiar (PEAAF) materializa em sua proposta pedagógica os preceitos da Educação Ambiental Crítica. Trata-se de uma pesquisa documental, em uma abordagem qualitativa, utilizando o método de análise de conteúdo. Com base nos dados obtidos, evidencia-se que o PEAAF propõe o desenvolvimento de ações educacionais ambientais a partir da sugestão de temas orientadores e pela adoção, de maneira integrada, do enfoque territorial, da pesquisa-ação participante, da investigação de temas geradores e da educomunicação como estratégias pedagógicas. Nesse sentido, orienta suas ações para o desvelamento e a problematização do meio ambiente em sua complexidade, em práticas que permitam a reflexão e a participação ativa na resolução de problemas socioambientais, buscando instrumentalizar os agentes sociais para a ação política e social transformadora, o que consiste em um posicionamento compatível com a Educação Ambiental Crítica.
\end{abstract}

Palavras-chave: PEAAF; Política Pública; Estratégias Pedagógicas; Problemáticas Socioambientais; Meio Ambiente.

Abstract: This article aims to analyze how the Programa de Educação Ambiental e Agricultura Familiar (PEAAF) materializes in its pedagogical proposal the Critical Environmental Education precepts. It is a documentary research, using a qualitative approach, following the content analysis method. Based on the data obtained, it is evident that the PEAAF proposes the development of environmental educational actions based on the suggestion of guiding themes, and by adopting, in an integrated manner, the territorial approach, participatory action research, the investigation of generating themes and the educommunication as pedagogical strategies. In this sense, it guides its actions towards the unveiling and problematization of the environment in its complexity, in practices that allow for the reflection and active participation in the resolution of socioenvironmental problems, seeking to equip social agents for transforming political and social action, which consists in a position compatible with Critical Environmental Education.

Keywords: PEAAF; Public Policy; Pedagogical Strategies; Socioenvironmental Issues; Environment.

\footnotetext{
1Universidade Federal do Vale do São Francisco. E-mail: alane.oliveira@univasf.edu.br. Link para o Lattes: http://lattes.cnpq.br/9957210941967443.

2 Universidade Federal do Vale do São Francisco. E-mail: Iiliane.ferreira@univasf.edu.br. Link para o Lattes: http://lattes.cnpq.br/1056299503564140.
} 


\section{Introdução}

A Educação Ambiental (EA) tornou-se um elemento essencial da educação nacional após a promulgação da Constituição Federal (1988). Em seu artigo 225, a Constituição reconheceu o direito de todos ao meio ambiente ecologicamente equilibrado e imputou ao poder público e à coletividade, a defesa e a preservação do meio ambiente. Além disso, estabeleceu a obrigação de o Poder Público "promover a Educação Ambiental em todos os níveis de ensino e a conscientização pública para a preservação do meio ambiente" (BRASIL, 1988, [s.p]). Posteriormente, em 1999, a EA se consolidou enquanto política pública, por meio da publicação da lei que instituiu a Política Nacional de Educação Ambiental (PNEA).

No contexto da PNEA, a EA consiste em "processos por meio dos quais o indivíduo e a coletividade constroem valores sociais, conhecimentos, habilidades, atitudes e competências de conservação do ambiente" (BRASIL, 1999, [s.p]), devendo estar presentes em espaços formais e não formais de ensino. Essa política estabeleceu que, nos espaços não formais de ensino, a EA deve fomentar "ações e práticas educativas que promovam a sensibilização da coletividade sobre as questões ambientais, à sua organização e participação na defesa da qualidade do meio ambiente" (BRASIL, 1999, [s.p]), envolvendo, dentre outros, os agricultores e as populações tradicionais.

Mas apenas com a reinvindicação do movimento de agricultores e agricultoras familiares, durante o evento Grito da Terra no ano de 2009, foi criado um programa específico para atender a esse setor. Ao propor ações governamentais que promovessem o fortalecimento da agricultura familiar, 0 movimento indicou a necessidade de um programa de EA. Essa reivindicação culminou na criação, em 2012, do Programa de Educação Ambiental e Agricultura Familiar (PEAAF), cujo objetivo principal é a promoção de ações educativas voltadas para a construção coletiva de estratégias no enfrentamento da problemática socioambiental rural (BRASIL, 2015b).

O programa se apresenta como uma alternativa para reorientar 0 desenvolvimento rural, que tem sido pautado por modelos de produção ambientalmente insustentáveis e socialmente injustos, promovendo a exaustão dos recursos naturais disponíveis e dificultando a permanência das famílias no campo. Esse padrão de produção gera um quadro degradante para o ambiente e para os agricultores, inviabiliza o acesso igualitário aos bens comuns, além de resultar na insegurança alimentar e em dificuldades econômicas que levam ao êxodo das famílias de agricultores (BRASIL, 2015b).

Ressalta-se ainda que a agricultura familiar tem assumido um importante papel no contexto do meio rural brasileiro, caracterizado pela alta concentração de pobreza, justamente em virtude de seu papel relevante para a segurança alimentar, para a ocupação no campo e para a distribuição de renda (SAMBUICHI et al., 2014). Por isso, é fundamental estimular o seu fortalecimento, reduzindo suas vulnerabilidades para garantir a sua viabilidade. 
Nesse contexto, torna-se essencial "equacionar a proteção do meio ambiente, suas múltiplas formas de uso dos recursos naturais e a garantia de condições dignas de vida no meio rural" (BRASIL, 2015a, p. 7). E isso perpassa uma transformação do modo de pensar e agir social, que se reflita na construção de uma nova forma de se relacionar em sociedade e com o meio

ambiente. É, justamente nesse sentido que o PEAAF se propõe a contribuir com o enfrentamento da problemática socioambiental rural, buscando a sustentabilidade da agricultura familiar.

No entanto, para tornar-se um instrumento efetivo, tal como previsto pela legislação nacional, a EA não pode se limitar à mera transmissão de conhecimentos sobre os processos naturais, ao incentivo para que as pessoas amem ou respeitem a natureza, a normatizar o comportamento diante da natureza, ou mesmo, a servir como estratégia para resolução de problemas ambientais pontuais. A EA deve afirmar valores e ações que possam contribuir para a transformação humana e social e para a preservação ecológica, estimulando a formação de sociedades sustentáveis, socialmente justas e ecologicamente equilibradas (FÓRUM INTERNACIONAL DAS ONGs, 1995). Propõe-se, com isso, que apenas a Educação Ambiental, em sua vertente crítica, pode estabelecer um processo educativo compatível com essa intencionalidade.

Mediante o exposto, faz-se necessário estabelecer respostas teóricas e práticas que criem oportunidades educativas coerentes com o previsto na Educação Ambiental Crítica. A partir dessa constatação, surgiu a seguinte indagação de pesquisa: de que modo o PEAAF materializa, em sua proposta pedagógica, os preceitos da vertente crítica da EA? Assim, esse artigo teve como objetivo analisar como o Programa de Educação Ambiental e Agricultura Familiar materializa, em sua proposta pedagógica, os preceitos da Educação Ambiental Crítica.

\section{Programa de Educação Ambiental e Agricultura Familiar}

O Programa de Educação Ambiental e Agricultura Familiar (PEAAF) foi criado para atender à necessidade de formação, capacitação, comunicação e mobilização da agricultura familiar e fomentar o desenvolvimento rural sustentável. Assim, por intermédio do desenvolvimento de ações educativas, o PEAAF mobiliza os grupos sociais para o entendimento e o enfrentamento coletivo de problemáticas socioambientais com os quais estão relacionados, buscando estimular a transformação das relações sociais e produtivas no meio rural que concorram para a promoção da sustentabilidade nos territórios rurais brasileiros e para a melhoria da qualidade de vida no campo (BRASIL, 2015b).

Como bem nos assegura Flores e Tybusch (2017), é um programa voltado para a difusão de práticas sustentáveis no território rural. Nesse sentido, para contribuir com o enfrentamento da problemática socioambiental rural, o PEAAF assume o propósito de fomentar processos educacionais críticos e participativos, tendo, por referência, a produção em bases

revista brasileira educação ambiental 
agroecológicas e práticas produtivas sustentáveis como alternativa para estimular o desenvolvimento rural sustentável e apoiar a regularização ambiental das propriedades rurais do país, no âmbito da agricultura familiar (BRASIL, 2015b).

O programa é dirigido à agricultura familiar e outros atores que se relacionam a esse segmento, em consonância com a Lei nํ⒒326, de 24 de julho de 2006. Nesse sentido, estão incluídos, no programa, dentre outros, silvicultores, aquicultores, extrativistas, pescadores, comunidades quilombolas, assentados e acampados da reforma agrária, além de povos e comunidades tradicionais. Esse programa também atende membros de organizações representativas da agricultura familiar e os agentes envolvidos com atendimento às demandas desse segmento.

O PEAAF atua a partir de cinco linhas de ação, que incluem a articulação com órgãos, políticas, planos e outros programas federais, o apoio à elaboração e à implementação de ações nos estados e territórios, o apoio a processos educativos presenciais e a distância, o fomento de projetos de Educação Ambiental, bem como a comunicação em Educação Ambiental para a agricultura familiar. A implementação dessas ações envolve 0 estabelecimento de articulações e parcerias com diversas instituições públicas e privadas e representações da agricultura familiar, nos âmbitos Federal, Estadual e Territorial. Além disso, busca-se, em todas as esferas, a articulação com movimentos sociais do campo e organizações da agricultura familiar com o propósito de fortalecer a participação e o controle social das políticas públicas (BRASIL, 2015b).

Assim, de acordo com Leão (2014, p.31), a implementação do programa é realizada:

por meio do envolvimento e da participação dos atores sociais, instituições e organizações e interlocutores da agricultura familiar, em uma dinâmica de corresponsabilidade, descentralização e desconcentração das suas ações. Dessa forma, a estrutura de capilaridade do Programa parte do âmbito federal para o estadual e finaliza no âmbito territorial onde efetivamente ocorrerá a sua aplicação prática.

Em seu contexto, são desenvolvidas práticas de Educação Ambiental por meio de atividades presenciais e semipresenciais. As presenciais envolvem o diagnóstico socioambiental, planejamento e monitoramento participativo, garantindo-se espaços de formação social e política dos envolvidos. Na educação presencial, também são realizadas formações em técnicas de manejo agroecológico por meio de atividades de campo e implantação de unidades demonstrativas (LEÃO, 2014). As atividades semipresenciais envolvem ações de capacitação referentes às metodologias e temáticas trabalhadas pelo referido programa e ocorrem por intermédio do Ambiente 
Virtual de Aprendizagem do Ministério do Meio Ambiente, sendo intercalado com momentos presenciais.

Desse modo, esse programa materializa a contribuição da PNEA à demanda socioambiental da agricultura familiar. Procura estabelecer o enfrentamento coletivo da problemática socioambiental rural, buscando a sustentabilidade da agricultura familiar. E, para isso, mobiliza e articula os atores sociais, governos estaduais e municipais, instituições e organizações representantes da agricultura familiar no desenvolvimento de ações educativas que primam pela transformação no contexto societário e produtivo do meio rural.

Ressalta-se, por fim, que o PEAAF orienta a atuação do trabalho coletivo dos diversos parceiros envolvidos nas suas ações a partir de sua proposta pedagógica. Acredita-se, conforme proposto por Souza (2015), que seja essencial problematizar como a EA, um campo múltiplo em referências e metodologias, interage com as discussões, problemáticas e os atores sociais da agricultura familiar. Investigar os aspectos norteadores dessa proposta e sua aproximação com a EA crítica, permite-nos compreender se o programa dissemina uma prática pedagógica coerente com o enfrentamento ao qual se propõe.

\section{Educação Ambiental crítica}

A EA Crítica é uma macrotendência que contempla diversas correntes como a EA Popular, EA Emancipatória, EA Transformadora e o Processo de Gestão Ambiental. Essa vertente insurge-se contra os mecanismos de dominação do ser humano e de acumulação de capital, buscando o enfrentamento das desigualdades e injustiças socioambientais. Em oposição às tendências conservadoras e conservacionistas, procura-se firmar na contextualização e na politização do debate ambiental, articulando as diversas dimensões da sustentabilidade e problematizando as contradições dos modelos de desenvolvimento e de sociedade (LAYRARGUES; LIMA, 2011).

De acordo com Loureiro e Layrargues (2013, p.64):

A Educação Ambiental crítica, é aquela que em síntese busca pelo menos três situações pedagógicas: a) efetuar uma consistente análise da conjuntura complexa da realidade a fim de ter os fundamentos necessários para questionar os condicionantes sociais historicamente produzidos que implicam a reprodução social e geram a desigualdade e os conflitos ambientais; b) trabalhar a autonomia e a liberdade dos agentes sociais ante as relações de expropriação, opressão e dominação próprias da modernidade capitalista; c) implantar a transformação mais radical possível do padrão societário dominante, no qual se definem a situação de degradação intensiva da natureza e, em seu interior, da condição humana. 
Desse modo, mudar o curso da crise ambiental em que vivemos não envolve apenas o estabelecimento de uma nova relação entre o ser humano e a natureza, impõe uma transformação no contexto societário a partir de uma renovação no conhecimento, nas instituições, nas relações sociais e políticas e nos valores culturais e éticos. Em vista disso, essa vertente se propõe a desvelar todo esse sistema complexo em que consiste o meio ambiente, incluindo, no debate ambiental, a dimensão político-ideológica dos mecanismos de reprodução social e a influência das relações socioculturais e das classes historicamente construídas nas questões ambientais. Espera-se, com isso, instrumentalizar os sujeitos com uma leitura abrangente e crítica da realidade para sua inserção política no processo de transformação socioambiental, numa perspectiva de formação para a cidadania, tencionando estimular um movimento coletivo em prol da construção de uma nova sociedade ambientalmente sustentável (LOREIRO; LAYRARGUES, 2013; GUIMARÃES, 2004).

Inspirada nos ideais que fundamentam as pedagogias críticas, há a defesa de uma pedagogia em que a educação e o conhecimento constituem uma construção dialógica e coletiva que visa ao desenvolvimento do pensamento crítico, à formação de sujeitos emancipados e à transformação da realidade sociocultural e política. Uma concepção educativa que, em função de sua natureza, estabelece um diálogo com a vida comunitária (LIMA, 2009) e vincula-se a "um outro modo de conhecer", em que o "ato pedagógico seja um ato de construção coletiva do conhecimento sobre a realidade, num processo dialético de ação-reflexão, ou seja, de exercício da práxis" (QUINTAS, 2004, p.133).

Enquanto projeto educativo interessado na transformação da sociedade, as ações pedagógicas da EA crítica devem superar a simples transmissão de conhecimentos ecologicamente corretos e o incentivo à afetividade dos sujeitos pela natureza, assumindo que a educação deve servir à mediação na construção social de conhecimentos envolvidos na vida dos sujeitos. Imersa na vida, história e questões urgentes de nosso tempo, deve se orientar para a compreensão das relações sociedade-natureza e para a intervenção sobre os problemas e conflitos ambientais (GUIMARÃES, 2004; CARVALHO, 2004).

Desse modo, essa vertente evidencia a educação como um processo permanente, cotidiano e coletivo pelo qual os indivíduos devem agir e refletir, transformando a realidade de vida. Para isso, busca promover ambientes educativos que favoreçam o desvelamento da realidade e a intervenção sobre ela e seus problemas socioambientais, buscando superar as armadilhas paradigmáticas e garantir um processo educativo em que, educandos e educadores possam se formar e contribuir, pelo exercício da cidadania ativa, com a transformação da grave crise socioambiental (LOUREIRO, 2004; GUIMARAES, 2004).

Trata-se de um processo educativo por meio do qual o indivíduo, em uma ação coletiva, transforma-se e transforma a realidade. Em seu contexto, são priorizadas pedagogias problematizadoras do cotidiano, enfatizado 0 
reconhecimento das diversidades socioculturais, estimulada a participação e o exercício da cidadania. Entende-se que esse é um meio para definir caminhos democráticos, sustentáveis e justos para todos. Adota a crítica e a ação política, procurando estabelecer movimentos emancipatórios e de transformação social que redefinam as relações sociais e a relação do homem com o meio ambiente (LOUREIRO, 2004).

Em vista disso, o projeto político-pedagógico da EA crítica pretende contribuir com a mudança de valores e atitudes, no intuito de formar um sujeito ecológico, um tipo de subjetividade que se orienta por sensibilidades solidárias com o meio social e ambiental. Esse é o modelo proposto pela EA crítica para formação de indivíduos e grupos sociais capazes de identificar, problematizar e agir em relação às questões socioambientais a partir de uma ética preocupada com a justiça ambiental (CARVALHO, 2004, p. 19). Para a EA crítica, esse pode configurar um dos caminhos de transformação em que há convergência entre mudança social e ambiental.

A partir desses apontamentos, pode-se compreender os preceitos que referenciam tal prática pedagógica, uma macrotendência que se pauta pelo desvelamento e pela problematização da complexidade que compõe o meio ambiente, buscando instrumentalizar os sujeitos para que possam empreender transformações significativas na realidade socioambiental. Faz-se necessário apresentar esses preceitos para subsidiar a análise da articulação da proposta pedagógica do PEAAF com essa vertente da EA.

\section{Metodologia}

O estudo aqui apresentado faz parte de pesquisa de dissertação de mestrado em andamento, realizada junto ao Programa de Pós-Graduação em Dinâmicas de Desenvolvimento do Semiárido, que analisa o Programa de Educação Ambiental e Agricultura Familiar.

Trata-se de uma pesquisa exploratória de caráter descritivo, de modo a proporcionar uma visão mais aproximada do objeto de estudo, tornando-o mais explícito, conforme proposto por Gil (2008). Quanto ao tipo de abordagem, optou-se pela pesquisa qualitativa, considerando o entendimento de Godoy (1995), de que este tipo de pesquisa envolve a obtenção de dados descritivos por meio do contato direto do pesquisador com a situação investigada, com vista à compreensão dos fenômenos.

Os dados foram obtidos a partir de uma pesquisa documental, cujo propósito foi de levantar as informações que pudessem subsidiar a análise da proposta pedagógica do PEAAF. Após transcritas e organizadas, as informações coletadas foram analisadas a partir da metodologia de análise de conteúdo e com auxílio do software ®ATLAS.ti.

Segundo Bardin (2016), a análise de conteúdos permite, por meio de procedimentos sistemáticos e objetivos, descrever e interpretar conteúdos de mensagens. Essa análise compreende as seguintes fases: pré-análise;

revista brasileira educação ambiental 
exploração do material; tratamento dos resultados obtidos e a interpretação. A pré-análise consiste na leitura flutuante, escolha dos documentos, definição das hipóteses, referenciação dos índices e elaboração dos indicadores. A exploração do material consiste na etapa em que o pesquisador realiza as operações de codificação, decomposição ou enumeração, em função das regras definidas na etapa anterior. No tratamento dos resultados e interpretação, os dados são classificados em virtude da relevância e, a partir disso, são propostas inferências e realizadas interpretações.

Para atender ao propósito desta pesquisa, dentre as técnicas de análise de conteúdo, foi utilizada a técnica de análise categorial temática. Essa técnica consiste em encontrar os "núcleos de sentido" na comunicação, que podem ter significação para objetivo analítico escolhido. Ressalta-se que a categorização a partir de tema é amplamente usada como unidade de registro para estudar motivações de opiniões, de atitudes, de valores, de crenças, de tendências etc. (BARDIN, 2016). E, segundo Bardin (2016, p.201), a análise temática representa uma opção "rápida e eficaz na condição de se aplicar a discursos diretos (significações manifestas) e simples".

\section{Resultados e discussão}

Numa perspectiva de contribuir para o enfrentamento da problemática socioambiental no meio rural, o PEAAF optou por um processo educativo orientado para promover e fortalecer o protagonismo dos agricultores familiares, tornando-os "agentes estratégicos de desenvolvimento territorial, capazes de refletir criticamente, propor soluções, se articular [sic], participar ativamente dos espaços de decisão e transformar a realidade social' (BRASIL, $2015 \mathrm{a}, \mathrm{p} .15-16$ ). Com isso, pretende superar uma prática que fomente o simples enquadramento dos sujeitos a padrões estabelecidos e a troca de técnicas de produção, incentivando-os a "adesão a um processo autônomo de construção pessoal e participação na transformação de sua realidade social e ambiental' (BRASIL, 2015a, p. 17).

Ademais, vale ressaltar que, no contexto do PEAAF, a Educação Ambiental é considerada como um:

pilar da atuação do Estado, que busca a intervenção qualificada, coletiva e organizada dos grupos sociais, garantindo que o processo de ensino-aprendizagem seja um ato de construção coletiva do conhecimento sobre a realidade num processo dialético de ação e reflexão, ou seja, de exercício da práxis (BRASIL, 2015a, p.17).

Nesse sentido, o processo educativo proposto pelo PEAAF busca promover a compreensão da conjuntura complexa que envolve o meio ambiente, por intermédio de práticas que favorecem a reflexão crítica e a participação ativa na resolução de problemas socioambientais relevantes para 
os grupos sociais, instrumentalizando-os para a atuação autônoma. Propõe-se, para isso, um processo dialógico e coletivo, caracterizado por não hierarquizar educadores e educandos, baseado no respeito a todas as formas de vida e que oportunize um aprendizado contextualizado, feito a partir da realidade dos próprios sujeitos envolvidos. Um processo, por meio do qual ampliam-se as oportunidades para a troca de conhecimentos e aprendizados mútuos e dinâmicos, fortalecem-se as buscas e articulam-se as capacidades. Esse é o processo proposto por esse programa para "formar cidadãos capazes de empreender uma leitura crítica do mundo e, a partir de suas ações, tecer as mudanças desejadas, exercendo influência sobre decisões governamentais e a dinâmica societária" (BRASIL, 2015a, p. 16).

E, para compatibilizar as práticas desenvolvidas pelos diferentes parceiros com o delineamento proposto, o PEAAF orienta o desenvolvimento dessas ações educativas por meio de sua proposta pedagógica (PP-PEAAF). A análise dos dados referente à PP-PEAAF permitiu a descrição, ora apresentada, dos aspectos norteadores das ações desse programa, de maneira a subsidiar entendimento do seu alinhamento com a vertente crítica da EA, objetivo assumido por esta pesquisa. Essa análise levou a criação de duas categorias, macrotemas e estratégias pedagógicas, sendo que a primeira categoria é formada por quatro subcategorias.

Com o propósito de possibilitar uma melhor compreensão, apresentamos abaixo uma breve síntese das categorias que emergiram nesse processo de análise (Quadro 1).

Quadro 1: Síntese das Categorias e Subcategorias.

\begin{tabular}{|c|c|c|}
\hline CATEGORIAS & SUBCATEGORIAS & TEMAS \\
\hline $\begin{array}{l}\text { 1. MACROTEMAS } \\
\text { Temáticas amplas } \\
\text { adotadas pelo } \\
\text { PEAFF que } \\
\text { orientam as ações } \\
\text { a serem } \\
\text { desenvolvidas no } \\
\text { âmbito dos } \\
\text { Estados e } \\
\text { Municípios. }\end{array}$ & $\begin{array}{l}1.1 \text { A problemática } \\
\text { rural no Brasil }\end{array}$ & $\begin{array}{l}\text { Os obstáculos e desafios para a Agricultura } \\
\text { Familiar (AF) no contexto de hegemonia de } \\
\text { modelos de produção rural ambientalmente } \\
\text { insustentáveis e socialmente injustos; conflitos } \\
\text { rurais; a Reforma Agrária; o pacote tecnológico da } \\
\text { Revolução Verde; os impactos da Agricultura } \\
\text { Contemporânea sobre o meio ambiente; a relação } \\
\text { campo - cidade; o uso intensivo de agrotóxicos e } \\
\text { sementes transgênicas; os movimentos sociais do } \\
\text { campo; a concentração da terra e o êxodo rural; } \\
\text { questões raciais, geracionais e de gênero que } \\
\text { conformam os territórios rurais; a participação da } \\
\text { AF na produção de alimentos para os brasileiros; a } \\
\text { ocupação de mão de obra no campo; a produção, } \\
\text { comercialização e distribuição de sementes; a } \\
\text { manipulação de recursos genéticos, em } \\
\text { contraposição à repartição justa de benefícios } \\
\text { prevista na Convenção da Diversidade Biológica; } \\
\text { as políticas públicas voltadas ao desenvolvimento } \\
\text { rural, entre outras. }\end{array}$ \\
\hline
\end{tabular}

Continua... 
Obstáculos e desafios para a reprodução social, econômica e cultural das populações tradicionais

1.2 A questão ambiental no contexto das populações tradicionais e da Agricultura Familiar no Brasil

\section{MACROTEMAS}

Temáticas amplas adotadas pelo PEAFF que orientam as ações a serem desenvolvidas no âmbito dos Estados e Municípios. no Brasil; os sistemas produtivos tradicionais; a relação entre as práticas tradicionais $\mathrm{e}$ a conservação da biodiversidade; as formas de organização e de agroecossistemas no contexto da AF; as políticas públicas para o fortalecimento da AF; as Unidades de Conservação de Uso Sustentável; as Reservas Extrativistas e a posse coletiva da terra; a Justiça Ambiental; a sociobiodiversidade; as redes de troca de sementes nativas e crioulas etc.

A gestão ambiental pública; a apropriação e o uso dos recursos ambientais por diferentes classes e grupos sociais; o desmatamento e a regularização ambiental; os impactos da ação humana sobre bacias hidrográficas; o uso extensivo de terras; contaminação dos solos e das águas; a participação e o controle social no processo de licenciamento ambiental de empreendimentos públicos e privados; os instrumentos de gestão ambiental relacionados à PNMA, à $\mathrm{PNRH}$, à PNMC, à PNRS etc.

A produção em bases agroecológicas e 0 desenvolvimento de tecnologias sociais e de práticas produtivas sustentáveis no meio rural; a agroecologia como ciência/área de conhecimento; a agroecologia versus agronegócio;

1.4 Agroecologia, a segurança e soberania alimentar e nutricional, as Tecnologias deliberações e resoluções da Conferência e do Sociais e Conselho Nacional de Desenvolvimento Atividades Sustentável da Agricultura Familiar (Condraf); os Produtivas modos de vida, tradições culturais e saberes das Sustentáveis populações rurais; o trabalho cooperativo; políticas públicas relacionadas à agroecologia e atividades produtivas sustentáveis, como a PNAPO; a PNATER; o PRONAF; o PRONAE; o PRONAA; o Programa Federal de Manejo Florestal Comunitário e Familiar.

\section{ESTRATÉGIAS} PEDAGÓGICAS

Estratégias que orientam o processo educacional no âmbito do PEAAF, devendo ocorrer de maneira integrada.

Educomunicação; Enfoque Territorial; Investigação de Temas Geradores; e Pesquisa-ação Participante. 
Evidencia-se que o PEAAF propõe o desenvolvimento de ações educacionais ambientais que contemplem a abordagem de macrotemas que contextualizam a problemática socioambiental no meio rural e estratégias pedagógicas específicas. Os macrotemas se desdobram em diversas temáticas que são apresentadas como sugestão para pautar as reflexões a serem desenvolvidas nessas ações. $E$, no caso das estratégias pedagógicas, são incentivadas a adoção do enfoque territorial, a investigação de temas geradores, pesquisa-ação participante e educomunicação. Essas categorias serão discutidas a seguir.

\section{Macrotemas}

A categoria 1, macrotemas, conforme definida no Quadro 1, compreende temáticas amplas que têm um papel preponderante na contextualização das demandas e dos desafios do cenário rural brasileiro nas ações do programa. Tem como objetivo subsidiar a elaboração dos processos educacionais nos âmbitos dos estados, territórios e municípios, a partir da sugestão de temas orientadores a serem abordados na investigação de temas geradores e em outras práticas pedagógicas.

A subcategoria 1.1, denominada "a problemática rural no Brasil", trata de questões relacionadas ao contexto rural brasileiro, em especial, dos reflexos do modelo de desenvolvimento adotado no meio ambiente e na dinâmica social e econômica no campo. Envolve temas relacionados à participação da agricultura familiar na economia e na segurança alimentar do país, impactos ambientais decorrentes dos modelos hegemônicos de produção, políticas públicas voltadas para o campo, bem como questões sociais que envolvem o meio rural. Com isso, possibilita o conhecimento e a reflexão sobre as determinantes que o cenário rural impõe à agricultura familiar.

Por sua vez, a subcategoria 1.2, "a questão ambiental no contexto das populações tradicionais e da Agricultura Familiar no Brasil", pauta -se pela dinâmica social das comunidades tradicionais e camponesas, internalizando questões específicas das populações tradicionais e da agricultura familiar, numa perspectiva de reconhecimento da diversidade cultural dessas comunidades e do direito à cidadania. As temáticas orientadoras envolvem o contexto social, econômico e cultural dessas populações, sistemas produtivos tradicionais, uso sustentável da biodiversidade e as políticas públicas para a agricultura familiar, além da justiça ambiental. Sendo assim, estimula a reflexão sobre a necessidade de garantir a reprodução social dessas comunidades, fortalecendo práticas sustentáveis no âmbito da agricultura familiar.

A subcategoria 1.3, "prevenção e mitigação de riscos e danos socioambientais", subscreve-se a partir da necessidade de enfrentamento do quadro ambiental provocado pelo modelo hegemônico de produção de alimentos e de promover a gestão ambiental pública. Refere-se a questões 
fundamentais à prevenção e mitigação de riscos e danos socioambientais e à necessária participação da coletividade na gestão ambiental. São indicados temas relacionados à gestão ambiental pública, apropriação e uso dos recursos ambientais, processos de regularização ambiental e licenciamento de empreendimentos e instrumentos de gestão ambiental relacionados às políticas públicas da área ambiental. Favorece, portanto, a reflexão sobre a necessária responsabilidade da sociedade na manutenção de um ambiente ecologicamente equilibrado e da importância do controle social sobre o uso dos recursos naturais.

Por fim, a subcategoria 1.4, "agroecologia, tecnologias sociais e atividades produtivas sustentáveis", ancora-se na necessidade de apresentar alternativas ao estilo dominante de agricultura que alimenta a crise socioambiental da atualidade. Trata da difusão de práticas produtivas sustentáveis no âmbito da agricultura familiar, apontando o uso de tecnologias sociais e a agroecologia como alternativas capazes de melhorar a qualidade de vida das comunidades rurais e de conduzi-las na transição para um sistema produtivo sustentável. Nesse sentido, aborda temas relacionados à difusão da agroecologia, tecnologias sociais e outras práticas sustentáveis, a exemplo daquelas provenientes da cultura das populações tradicionais. Além disso, contempla questões como a segurança alimentar, políticas públicas relacionadas à agroecologia e atividades produtivas sustentáveis e, ainda, as deliberações da Conferência e do Conselho Nacional de Desenvolvimento Sustentável da Agricultura Familiar (Condraf). Portanto, põe em debate alternativas que possam harmonizar a prática produtiva com a conservação ambiental e as estratégias governamentais adotadas para difundi-las.

Assim, a categoria Macrotemas apresenta temáticas com o propósito de nortear as ações vinculadas ao PEAAF. Essas temáticas abrangem questões relacionadas ao contexto rural brasileiro, às especificidades das populações tradicionais e da agricultura familiar, à prevenção e à mitigação de riscos e danos socioambientais, à participação da coletividade na gestão ambiental e também abarcam a difusão de práticas produtivas sustentáveis no âmbito da agricultura familiar. Com isso, estimula a reflexão sobre a dinâmica de desenvolvimento brasileira e o modelo de produção de alimentos por ele privilegiado, os efeitos desse modelo na biodiversidade, o espaço da agricultura familiar nesse contexto e sobre o necessário enfrentamento desse quadro, em especial, dentre outros aspectos, com a participação efetiva da coletividade e com o fortalecimento das práticas sustentáveis na agricultura familiar.

Nesse sentido, é preciso ressaltar que, no contexto da PP-PEAAF, fomentar a transformação socioambiental implica a superação do desenvolvimento de processos educativos que envolvam os sujeitos no estudo e na preservação do meio ambiente. Esses processos estão associados a uma visão reducionista e fragmentada da realidade que enfatiza a dimensão ecológica das questões ambientais. Em vista disso, ressalta os efeitos dos impactos ambientais, buscando a simples transmissão de conhecimentos e 
técnicas apropriados, além do estímulo à mudança de comportamento dos indivíduos em relação ao meio ambiente.

A abordagem do PEAAF privilegia o estabelecimento de processos que problematizem "a relação sociedade e natureza, as formas de uso e apropriação social dos recursos ambientais, a interdependência entre os aspectos históricos, econômicos, culturais e ambientais de determinada formação social' (BRASIL, 2015a, p. 17), incorporando, na discussão das problemáticas ambientais, as dimensões sociais, éticas, políticas e culturais, que lhes são inerentes e, portanto, indispensáveis a sua compreensão. Assim, evidencia os processos sociais que circunscrevem a questão ambiental e que contextualizam a problemática socioambiental no âmbito da agricultura familiar, de modo a estimular "não apenas a troca de técnicas de produção, mas a transformação do conjunto de relações sociais e produtivas existentes no meio rural' (BRASIL, 2015a, p.15).

Em uma perspectiva multidimensional e integradora, busca-se fomentar práticas educativas que promovam a compreensão do meio ambiente, considerando a complexidade e os múltiplos aspectos que o envolvem; dessa forma, uma abordagem conceitual de meio ambiente que encontra respaldo na EA crítica. Essa macrotendência privilegia um processo educativo que problematiza os contextos societários em sua interface com a natureza, evidenciando os problemas ambientais articulados aos conflitos sociais e assumindo, como causa constituinte dos problemas ambientais, as relações sociais e os modelos de sociedade e de desenvolvimento (LOREIRO; LAYRARGUES, 2013). Trata-se de uma perspectiva que traz a complexidade para a compreensão e para a intervenção, uma vez que se busca alcançar a totalidade complexa, constituinte das questões ambientais, para estabelecer reflexões abrangentes que favoreçam a compreensão crítica, tendo, como objetivo último, realizar uma transformação radical no contexto societário, o que impõe uma renovação multidimensional, tal como propõem Loureiro e Layrargues (2013).

Esse entendimento é reiterado por Guimarães (2016), ao apontar que a Educação Ambiental crítica assume uma visão sistêmica de meio ambiente, compreendendo-o em sua totalidade complexa, cujas partes interdependentes, interrelacionam-se. $O$ autor esclarece que, historicamente, o espaço natural vem sendo apropriado e transformado pelas sociedades, em consonância com as relações de poder decorrentes das relações sociais que se estabelecem nessas sociedades. Essas relações sociais, por sua vez, têm refletido uma postura antropocêntrica da humanidade e do modo de produção capitalista, em que prevalece a exploração do meio ambiente e do coletivo social em detrimento do interesse privado, e se sustentado dessa postura. A compreensão da realidade socioambiental envolve 0 desvelamento dessa complexa interação que compõe o meio ambiente, e o enfrentamento da crise ambiental demanda uma mudança de "valores, hábitos e atitudes, individuais e coletivos, de uma nova ética e novas relações de produção e consumo 
substanciadas em diferentes paradigmas" (p. 15) que concorram para uma transformação social e a construção de uma nova sociedade.

O PEAAF se aproxima da EA crítica na sua intenção de estabelecer o enfrentamento das problemáticas socioambientais no meio rural, buscando realizar transformações nas relações sociais e produtivas, a partir do estímulo ao desenvolvimento de práticas educativas que viabilizem a compreensão da conjuntura complexa que envolve o meio ambiente, entendendo que isso é imprescindível para a formação de sujeitos capazes de atuar nessa transformação. E com o desvelamento e a problematização do meio ambiente, em sua complexidade, que o programa espera instrumentalizar os sujeitos para participarem ativamente na transformação da realidade socioambiental.

\section{Estratégias Pedagógicas}

A análise de dados permitiu a identificação de quatro estratégias pedagógicas (categoria 2), as quais devem ser desenvolvidas de maneira integrada nos processos educacionais fomentados pelo programa. Além do enfoque territorial, esses processos devem contemplar a pesquisa-ação participante, a investigação de temas geradores e a educomunicação, considerando que essas estratégias podem propiciar a reflexão crítica, favorecendo uma ação coletiva, organizada e qualificada dos grupos sociais.

A temática "enfoque territorial" está relacionada à adoção do território como unidade de referência para as ações desenvolvidas no âmbito do PEAAF. Essa abordagem reflete uma visão integradora, por meio da qual o território deve ser compreendido como um espaço formado a partir da integração/relação de suas múltiplas dimensões, a econômica, a política, a cultural e a ecológica, tendo uma concepção de espaço como um híbrido entre sociedade e natureza; entre política, cultura e economia; entre a sua dimensão material e a simbólica (SOUZA, 2013). Assim, para além de espaço geográfico, o conceito de território envolve a compreensão de que as relações sociais que nele se estabelecem, bem como a ação humana sobre a natureza, conferem a esse espaço características econômicas, políticas e ambientais específicas, construindo uma identidade cultural para aqueles que nele vivem (BRASIL, 2015a).

Em vista disso, cada território compõe uma realidade única que deve ser considerada no escopo de suas ações, uma vez que os territórios não estão suscetíveis a processos e estímulos idênticos; cada um contempla um contexto que requer instrumentos e tratamentos específicos à natureza dos problemas e das soluções que esses demandam. Por isso, as ações vinculadas ao programa devem considerar, em seus processos de investigação, aprendizagem e intervenção, os aspectos ambientais, econômicos, políticos e culturais específicos do território para o qual se destinam essas ações. $E$, nesse sentido, propõe a realização de um diagnóstico socioambiental que busque conhecer as demandas sociais e 
ambientais da agricultura familiar de cada território, o que fornecerá o estabelecimento de ações alinhadas a cada contexto, permitindo que 0 programa atue de maneira assertiva em sua realidade concreta.

É necessário ressaltar que o entendimento do território é essencial para promover a compreensão integral do meio ambiente, pois, uma vez dominada pelos grupos humanos por meio da sua manipulação em processos que envolvem aspectos políticos, econômicos e culturais, a natureza torna-se componente do território e, como tal, passa a ser regida pelos interesses e pelas relações complexas que nele se estabelecem. São as relações territoriais que definem as diversas formas de apropriação e humanização da natureza, das quais decorrem os problemas ambientais (COSTA; MACIEL, 2006). Portanto, a compreensão do meio ambiente, em sua complexidade, perpassa pelo entendimento do território.

Desse modo, o enfoque territorial conduz a uma ação educativa orientada para 0 reconhecimento da diversidade sociocultural e para desenvolver uma abordagem complexa das questões ambientais, preceitos basilares da EA crítica. Como já foi discutido, segundo essa vertente, fomentar a compreensão complexa do real é fundamental para a instrumentalização dos atores sociais para uma intervenção qualificada nessa realidade. Além disso, o "reconhecimento das diferentes necessidades, interesses e modos de relações na natureza que definem os grupos sociais e o 'lugar' ocupado por estes em sociedade" (LOUREIRO, 2004, p.81), possibilita o estabelecimento de sínteses que definam caminhos democráticos, sustentáveis e justos para todos.

A temática "investigação de temas geradores", cuja principal referência é 0 autor Paulo Freire, refere-se a uma metodologia problematizadora da realidade concreta que busca superar a artificialidade e o caráter conteudista em que são tratados os temas, levando, aos sujeitos, uma dimensão significativa da sua totalidade. Nessa metodologia, os temas são contextualizados, carregados de significado social, cultural e histórico pertinentes para os educandos, numa perspectiva de despertar a sua consciência crítica de mundo e sobre sua própria realidade, incitando-os a uma ação transformadora.

O tema gerador é o ponto de partida na construção de descoberta que, substituindo os conteúdos tradicionais, são extraídos da prática de vida dos educandos e buscados a partir de seu universo vocabular. A denominação "geradores" ressalta a condição natural que os temas apresentam de se desdobrarem em outros temas, ampliando seu campo de possibilidades de reflexões, mas essa singularidade não contempla, em si, características suficientes para que o tema seja considerado "gerador". Para isso, devem gerar um processo de ação-reflexão-ação que considere os conteúdos sociais e políticos com significados concretos para os educandos, levando-os a um processo de conscientização da realidade opressora. Desse modo, essa metodologia serve à problematização de situações concretas, numa perspectiva de empreender um esforço para uma compreensão em um nível 
mais crítico da realidade por intermédio da reflexão coletiva, em um processo dialógico, democrático, participativo e emancipatório (BRASIL, 2015a, TOZONIREIS, 2006).

$\mathrm{Na}$ EA crítica, os temas ambientais não podem assumir o caráter dado pela pedagogia tradicional, em que os conteúdos são estabelecidos previamente e devem ser simplesmente transmitidos. Essa vertente demanda um tratamento mais vivo com vista à apropriação crítica, de modo que os conhecimentos devem ser construídos de "forma dinâmica, coletiva, cooperativa, contínua, interdisciplinar, democrática e participativa, pois somente assim pode contribuir para o processo de conscientização dos sujeitos para uma prática social emancipatória" (TOZONI-REIS, 2006, p.97). Nesse sentido, Tozoni-Reis (2006, p.98) defende essa metodologia problematizadora como uma importante diretriz para a EA crítica, por meio da qual "os temas ambientais locais devem ser tratados como temas geradores de reflexões mais amplas e consequentes para a formação crítica e transformadora dos sujeitos".

Reconhecendo a necessidade de subsidiar uma leitura complexa e abrangente da realidade para desenvolver a EA crítica, o PEAAF incorpora a investigação de temas geradores em sua proposta pedagógica. Assim, as práticas de Educação Ambiental do programa devem considerar e tomar como ponto de partida para os seus processos de investigação temáticas socioambientais relevantes para os grupos sociais atendidos pelo programa, de maneira que eles possam compreender os "determinantes sociais e históricos da agricultura familiar e dos problemas socioambientais do seu território" (BRASIL, 2015a, p.33). Com isso, espera-se avançar no sentido de empreender uma ação que contribua para fortalecer a consciência dos agricultores familiares sobre as causas dos problemas socioambientais a que estão submetidos e que os estimule a agir no sentido de superar esses problemas, exercitando a sua cidadania.

Dentro do contexto da categoria 2, a temática "pesquisa-ação participante" (PAP) corresponde a um tipo de pesquisa social em que se busca a participação ativa dos "sujeitos da pesquisa em um processo de reflexão, análise da realidade, produção de conhecimentos e enfrentamento dos problemas" (TOLEDO; JACOBI, 2013, p.156). Em seu contexto, os atores sociais são envolvidos na reflexão crítica da realidade em que se inserem, de modo a estimulá-los a questionarem suas práticas e encontrarem soluções para os seus problemas. Nesse processo, são produzidos conhecimentos e desenvolvidas novas habilidades e atitudes que influenciarão na ressignificação de valores e na transformação da situação, foco da investigação (TOLEDO; JACOBI, 2013).

A PAP articula, profunda e radicalmente, a produção de conhecimentos e a ação educativa, exigindo a participação radical dos sujeitos. Trata-se de um processo em que se dá, ao mesmo tempo, a produção de conhecimentos sobre a realidade e uma ação educativa participativa que visa ao enfrentamento dessa realidade. É uma modalidade de pesquisa que envolve os sujeitos no 
desafio de "pesquisar e participar, investigar e educar, compreender e transformar" (TOZONI-REIS, 2008, p.164). É, portanto, uma opção metodológica que assume um compromisso político com a emancipação e com a ação reflexiva, amparando-se em processo educativo que articula teoria e prática para desvelar a realidade e transformá-la, oportunizando, com isso, a aprendizagem e o exercício da cidadania (LOUREIRO, 2007).

Ao se manifestar a favor de uma abordagem crítica da EA, Tozoni-Reis (2008) defende que a pesquisa, nessa macrotendência, tem como principal objetivo "produzir conhecimentos sobre processos educativos críticos com compromisso de transformação das relações sociais e ambientais na perspectiva da emancipação" (p.159). Nesse sentido, sugere a pesquisa-ação participativa, nomeada como "participante", no caso de Loureiro (2007), como alternativa metodológica que compreende um processo original, complexo e dinâmico de produção de conhecimentos, adequada à consecução desse objetivo.

Desse modo, o PEAAF incorpora a PAP em sua dimensão pedagógica, com vistas a estimular a participação ativa dos agricultores em um processo único que contempla a tomada de consciência de sua própria realidade, a resolução de problemas concretos e a produção de conhecimento sobre esses problemas. Considera-se que esse tipo de pesquisa deve contribuir para a compreensão dos problemas e conflitos socioambientais existentes e das suas causas e, com isso, orientar os agricultores na busca de soluções que possam conduzi-los ao enfrentamento das situações que estes vivenciam.

Por fim, a temática "educomunicação" propõe que o diálogo da comunicação social e da educação se materialize na prática educativa por meio do uso consciente de tecnologias de informação e comunicação no processo de ensino-aprendizagem. Nesse sentido, as práticas educativas, no contexto do PEAAF, devem envolver os agricultores no desenvolvimento de instrumentos e metodologias de educomunicação, como uma estratégia para democratizar 0 acesso aos meios de comunicação e às informações pertinentes ao programa. Além disso, ressalta a importância de considerar os meios de comunicação existentes nos territórios, os quais possam potencializar a difusão de conhecimentos dos grupos sociais e aqueles que possam facilitar a construção de saberes de forma coletiva e colaborativa.

Nesse sentido, reconhece a importância da educomunicação na potencialização do uso de tecnologias da informação e comunicação para as transformações no meio rural. Por meio dessa estratégia, há um incentivo à produção e socialização coletiva do conhecimento, bem como à promoção de reflexões sobre as problemáticas socioambientais dos territórios. Porém, para além de estabelecer metodologias pedagógicas que possibilitem a reflexão e a investigação da realidade, pretende-se que os sujeitos se apropriem e passem a fazer uso autônomo desses meios como recurso de comunicação, instrumentalizando-os para intervir na sua realidade. 
A Educomunicação objetiva o desenvolvimento de ações que viabilizem a formação crítica para a produção, recepção e gestão de processos comunicacionais, potencializando o diálogo pedagógico com as mídias e a construção de ecossistemas comunicativos, uma ambiência que viabiliza a construção e a reconstrução do conhecimento em um processo de reflexão coletiva, constante e compartilhada do fazer pedagógico (SCHÖNINGER; SARTORI; CARDOSO, 2016). Assim, além de ser um instrumento de mediação para a construção de conhecimentos, favorece a apropriação crítica dos meios de comunicação e potencializa a capacidade comunicativa dos sujeitos.

Ela surge e se estrutura a partir de uma compreensão ideológica e libertadora da ação humana no mundo para transformá-lo. Desse modo, sua práxis prioriza a interação dialética entre as pessoas e suas realidades e o desenvolvimento da consciência social, por intermédio de um processo de ação-reflexão-ação em que se utilizam os diversos recursos comunicacionais para fomentar a problematização dessa realidade, numa perspectiva de formar e transformar. Assim, consolida-se como uma prática interessada na construção da cidadania, no desenvolvimento do pensamento crítico e na emancipação social, sendo um meio para praticar a comunicação ambiental e de lutar em favor de uma sociedade sustentável (FREITAS, 2015). Apresenta, portanto, características e intencionalidades que dialogam com os objetivos da EA crítica e que revelam o seu potencial de servir como metodologia para essa vertente.

Em síntese, a análise da categoria "estratégias pedagógicas" permite compreender o delineamento metodológico da PP-PEAAF para promover a mobilização dos grupos sociais, visando ao entendimento e ao enfrentamento das problemáticas socioambientais com os quais estão relacionados. Articulando o enfoque territorial, a investigação de temas geradores, a educomunicação e a pesquisa-ação participante, o PEAAF privilegia um processo educativo orientado para o fortalecimento do protagonismo dos agricultores familiares, estimulando a sua capacidade de reflexão crítica e a participação ativa na transformação da realidade socioambiental.

A PP-PEAAF articula teoria e prática, aprendizagem e ação social, estabelecendo um processo de reflexão coletiva sobre problemas socioambientais de cada território, em que a tomada de consciência e a produção de conhecimento sejam direcionadas à resolução de problemas concretos (FLORES; TYBUSCH, 2017). Vincula-se a uma concepção pedagógica em que educar constitui um ato de conhecimento da realidade concreta, em que há uma aproximação crítica com a própria realidade, cujas ações pedagógicas pretendidas são compreender, refletir, criticar e agir (TOZONI-REIS; 2006).

O enfoque territorial direciona as ações educativas para as demandas específicas de cada território, evidenciando uma compreensão das problemáticas socioambientais enquanto produto dos múltiplos aspectos e das complexas relações que se estabelecem em cada contexto territorial. E para 
concretizar, pedagogicamente, essa abordagem complexa, é adotada a investigação de temas geradores, em uma perspectiva de que os temas ambientais que tenham significado concreto para os envolvidos recebam um tratamento problematizador, de modo a estabelecerem reflexões abrangentes que permitam realizar uma consistente análise de sua complexidade, conforme propõem Loureiro e Layrargues (2013).

A educomunicação e a PAP estimulam a reflexão crítica e a ação participativa no enfrentamento dos problemas e dos conflitos ambientais em que os sujeitos estão envolvidos, integrando teoria e prática em um processo educativo coletivo, de caráter político, transformador e emancipatório. Criam oportunidades reais e concretas de participação ativa na difusão de conhecimentos ambientais, na produção de conhecimentos e na resolução de problemas. Nesse processo, ainda se instrumentaliza os sujeitos com importantes ferramentas para a compreensão da realidade que podem auxiliálos a atuar, de maneira autônoma, na construção do conhecimento e no enfrentamento da realidade socioambiental.

A partir dessas estratégias, estabelece-se um processo de açãoreflexão-ação, ocupado com a ação educativa e a ação-intervenção no contexto social. Coletivo, participativo e dialógico, esse processo oportuniza um aprendizado contextualizado, baseado na própria realidade do educando e fundamentado na práxis. Consiste, desse modo, em um ato pedagógico que envolve a construção coletiva do conhecimento sobre a realidade socioambiental (QUINTAS, 2004), não apenas para compreendê-la, mas também para transformá-la. Nesse sentido, reflete uma prática que pretende a formação da consciência crítica, o exercício pleno da cidadania e a emancipação social, entendendo-os como essenciais ao processo de transformação desta realidade.

Essa é a ação educativa proposta pelo PEAAF para formar cidadãos capazes de realizar uma leitura crítica do mundo e de agir no sentido de transformar a sua realidade socioambiental, uma ação que potencializa a compreensão de sua própria realidade, faz com que eles tomem consciência dos problemas e dos conflitos socioambientais com os quais estão relacionados e que aumenta a sua capacidade de tomar decisões e de intervir sobre ela. Espera-se, com isso, que eles passem a atuar de maneira autônoma, coletiva, organizada e qualificada, para empreender as mudanças desejadas. Daí, deduz-se a sua orientação para promover liberdade e autonomia dos agentes sociais (LOUREIRO; LAYRARGUES, 2013).

Assim, a partir da análise das categorias Macrotemas e Estratégias pedagógicas, percebe-se que a concepção de meio ambiente e do fazer pedagógico da Educação Ambiental, manifestos na PP-PEAAF, encontra respaldo na EA crítica. Essa proposta expressa princípios, atributos e intencionalidades que alinha as ações do programa aos preceitos dessa vertente. $\mathrm{E}$, de acordo com a síntese apresentada por Loureiro e Layrargues (2013), o PEAAF busca promover uma compreensão multidimensional e 
complexa do meio ambiente, desenvolver a autonomia e a liberdade dos agentes sociais frente às relações de poder que repercutem sobre a apropriação e o uso dos recursos naturais e contribuir para transformação radical no contexto societário.

Ao assumir o desafio de estabelecer o enfretamento da problemática socioambiental no meio rural, o PEAAF enfatiza, em sua proposta, uma concepção complexa do meio ambiente e adoção de pedagogias problematizadores do cotidiano, estimulando a reflexão e participação ativa na resolução de problemas socioambientais, procurando instrumentalizar os sujeitos para a ação política e social transformadora. Manifesta, explicitamente, um processo educativo que busca estimular transformações nas relações sociais e produtivas no meio rural, em um esforço de construção de sociedades sustentáveis, socialmente justas e ecologicamente equilibradas, afirmando, assim, um posicionamento compatível com a EA crítica.

\section{Considerações finais}

Esse artigo procurou refletir sobre a proposta pedagógica do PEAAF e sua articulação com os preceitos da Educação Ambiental Crítica. A análise aqui empreendida evidencia que o programa tem se orientado para o enfrentamento dos problemas socioambientais no meio rural, procurando estabelecer práticas educativas que possam contribuir, por meio da formação de sujeitos críticos e participativos, para a transformação da realidade socioambiental dos territórios rurais. Nesse sentindo, reflete uma ação voltada para uma mudança social e cultural, pela construção de conhecimentos, valores, atitudes e comportamentos, que possa concorrer para a atuação autônoma, consciente e ética ante o meio social e ambiental. Desse modo, contempla uma ação educativa que encontra respaldo na vertente crítica da EA.

É importante ressaltar que essa análise não teve a intenção de esgotar o assunto investigado nem de apresentar uma análise mais aprofundada das questões. No entanto, espera-se que seus resultados possam fomentar o debate sobre o PEAAF e ainda subsidiar a atuação dos diversos atores interessados na formulação e implementação de ações de Educação Ambiental, em especial, aquelas voltadas à agricultura familiar, no sentido de contribuir para o desenvolvimento de ações educativas ambientais pautadas nos princípios da EA crítica.

Como limitações deste estudo, citam-se a exclusividade da pesquisa documental e o escasso número de informações disponíveis sobre o PEAAF. Entretanto, considera-se que o estudo possibilitou demonstrar a aproximação da proposta pedagógica do programa com tal vertente. Novas investigações poderão aprofundar essa análise, em estudos que contemplem, como fonte de evidência, os próprios sujeitos das ações do programa, de modo que se possa compreender como sua proposta se evidencia na prática. 


\section{Referências}

BRASIL. Constituição da República Federativa do Brasil. Constituição da República Federativa do Brasil. Brasília, DF: Senado Federal: 1988. Disponível em: http://www.planalto.gov.br/ccivil 03/constituicao/constituicao.htm. Acesso em: 7 set. 2020.

BRASIL. Lei $\mathbf{n}^{\circ}$ 9.795, de 27 de abril de 1999. Dispõe sobre a Educação. Ambiental, institui a Política Nacional da Educação Ambiental e dá outras providências. Brasília, 1999. Disponível em: http://www.planalto.gov.br/ccivil 03/leis/19795.htm. Acesso em: 7 set. 2020.

BRASIL. Ministério do Meio Ambiente. Programa de Educação Ambiental e Agricultura Familiar: Caderno conceitual do PEAAF. Brasília: MMA, 2015a. Disponível em: $<$ http://www.nuredam.com.br/files/documentos $\mathrm{mec} / \mathrm{mma} /$ cadernoconceitual.pdf >. Acesso em: 6 mai. 2019.

BRASIL. Ministério do Meio Ambiente. Programa de Educação Ambiental e Agricultura Familiar. Brasília: MMA, 2015b. Disponível em: $<$ http://www.nuredam.com.br/files/documentos mec/mma/programapeaaf.pdf>. Acesso em: 6 mai. 2019.

BARDIN, L. Análise de Conteúdo. 3a Reimpressão da 1. ed. São Paulo: Edições 70, 2016.

CARVALHO, I.C.M. Educação Ambiental Crítica: Nomes e Endereçamentos da Educação. Identidades da Educação Ambiental. Brasília: MMA, p. 13-24, 2004.

COSTA, B.P.; MACIEL, J.L. O território como conceito-chave na Educação Ambiental-reflexões a partir do projeto comunitário" Jardim Botânico e a comunidade: preservando a flora nativa". Boletim Gaúcho de Geografia, v. 31, n. 1, 2006.

FLORES, A.G.; TYBUSCH, F.B.A. Educação Ambiental na Agricultura Familiar: um estudo sobre o PEAAF. Revista Jurídica da Faculdade de Direito de Santa Maria-FADISMA, Santa Maria, v. 12, n. 1, 2017.

FORUM INTERNACIONAL DAS ONGs. Tratado de Educação Ambiental para sociedades sustentáveis e responsabilidade global. Rio de Janeiro: Fórum das ONGs , 1992. Disponível em: http://portal.mec.gov.br/secad/arquivos/pdf/educacaoambiental/tratado.pdf.

Acesso em: 22 abr. 2019.

FREITAS, J.V. Educomunicação: contextualizando o processo de atribuição de sentidos e significados no delineamento do conceito. Revista Brasileira de Educação Ambiental, v. 10, n. 2, p. 149-162, 2015.

GIL, A.C. Métodos e técnicas de pesquisa social. 6. ed. Editora Atlas SA, 2008. 
GODOY, A.S. Introdução à pesquisa qualitativa e suas possibilidades. Revista de Administração de Empresas, São Paulo, v. 35, n. 2, p. 57-63, 1995.

GUIMARÃES, M. Educação Ambiental crítica. Identidades da Educação Ambiental brasileira. Brasília: MMA, p. 25-34, 2004.

GUIMARÃES, M. Por uma Educação Ambiental crítica na sociedade atual. Revista Margens Interdisciplinar, v. 7, n. 9, p. 11-22, 2016.

LAYRARGUES, P.P.; LIMA, G.F.C. Mapeando as macro-tendências políticopedagógicas da Educação Ambiental contemporânea no Brasil. Anais do Encontro Pesquisa em Educação Ambiental, v. 6, p. 1-15, 2011.

LEÃO, D.S. O Programa de Educação Ambiental e Agricultura Familiar (PEAAF) no assentamento Laranjeiras I, em região de nascentes do pantanalCáceres-MT. 2014. Tese de Doutorado. Universidade do Estado de Mato Grosso.

LIMA, G.F.C. Educação Ambiental crítica: do socioambientalismo às sociedades sustentáveis. Educação e Pesquisa, v. 35, n. 1, p. 145-163, 2009.

LOUREIRO, C.F.B. Educação Ambiental transformadora. Identidades da Educação Ambiental brasileira. Brasília: MMA, p. 65-84, 2004.

LOUREIRO, C.F.B. Pesquisa-ação participante e Educação Ambiental: uma abordagem dialética e emancipatória. In: TOZONI-REIS M.F.C. (org.). A pesquisa-ação-participativa em Educação Ambiental: reflexões teóricas. São Paulo: Annablume, p. 13-56, 2007.

LOUREIRO, C.F.B.; LAYRARGUES, P.P. Ecologia política, justiça e Educação Ambiental crítica: perspectivas de aliança contra-hegemônica. Trabalho, educação e saúde, v. 11, n. 1, p. 53-71, 2013.

QUINTAS, J.S. Educação no processo de gestão ambiental: uma proposta de Educação Ambiental transformadora e emancipatória. Identidades da Educação Ambiental brasileira. Brasília: MMA, p. 113-140, 2004.

SAMBUICHI, R.H.R. et al. A diversificação produtiva como forma de viabilizar o desenvolvimento sustentável da agricultura familiar no Brasil. In: MONASTERIO, L. M.; NERI, M. C.; SOARES, S. S. D. (ed.) Brasil em desenvolvimento 2014: Estado, planejamento e políticas públicas. 2 v. Brasília: Ipea, 2014. cap. 3, p. 61-84.

SCHÖNIN, R.R.Z.V.; SARTORI, A.S.; CARDOSO, F.L. Educomunicação e prática pedagógica educomunicativa: uma revisão sistemática. Cadernos de Pesquisa, v. 23, n. 1, p. 1-11, 2016.

SOUZA, I.H.S. Educação Ambiental e desenvolvimento territorial sustentável: entrelaçando políticas e práticas que envolvam educação, desenvolvimento e sustentabilidade no Território de Identidade Velho Chico/BA. 2013. 2015. Dissertação de Mestrado. Programa de Pós-Graduação em Educação e Contemporaneidade, UNEB. Salvador, 2013. 
SOUZA, N.A. Educação Ambiental e Agricultura Familiar: encontros, desafios e aprendizagens. MMA/Coleciona: fichário d@ Educador Ambiental, v. 1, n. 13 (maio 2015) Brasília, Edição Especial. 96 p., v. 1, n. 13, p. 37, 2015.

TOLEDO, R.F.; JACOBI, P.R. Pesquisa-ação e educação: compartilhando princípios na construção de conhecimentos e no fortalecimento comunitário para o enfrentamento de problemas. Educação \& Sociedade, v. 34, n. 122, p. 155-173, 2013.

TOZONI-REIS, M.F.C. Pesquisa-ação em Educação Ambiental. Pesquisa em Educação Ambiental, v. 3, n. 1, p. 155-169, 2008.

TOZONI-REIS, M.F.C. Temas ambientais como temas geradores: contribuições para uma metodologia educativa ambiental crítica, transformadora e emancipatória. Educar, n. 27, p. 93-110, 2006. 